\title{
Cómo reformar las reformas de las pensiones... y el coste de no hacerlo
}

\author{
Ignacio ZUBIRI \\ Universidad del País Vasco \\ ignacio.zubiri@ehu.eus
}

Recibido: 29-03-2015

Aceptado: 01-06-2015

\section{RESUMEN}

En España el equilibrio del sistema de pensiones se ha buscado reduciéndolas. Como resultado, se ha bajado la pensión inicial y el número de años durante los que se cobra la pensión. Peor aún, por el índice de revalorización, en el medio e incluso en el largo plazo el valor real de las pensiones disminuirá desde el momento de la jubilación. Esto, además de presuponer que los pensionistas carecen de derechos y hacerles cargar con todo el coste del envejecimiento, acabará conduciendo a una sociedad futura envejecida y empobrecida. Para evitar esto y respetar los derechos de los pensionistas futuros es necesaria una reforma sustancial que deshaga muchas de las medidas adoptadas y dote al sistema de pensiones de recursos adicionales (impuestos y otros recursos)

Palabras clave: pensiones, reforma, financiación, sostenibilidad

\section{How to reform pension reforms... and the cost of not doing it}

\begin{abstract}
The Spanish pension system will be balanced reducing pensions. As a result, the initial pension will lower and the retirement period will be smaller. Furhermore, due to the Index for Pension Revaluation, in the medium and even in the long run the real value of pensions will decrease continuously. All this, assumes that future pensioners don't have any rights and that they have to bear all the cost of ageing. In the end, this will lead to a society aged and impoverished. To avoid that and respect the rights of pensioners, a new reform is needed. This reform has to eliminate some of the measures taken and increase the resources of the system (taxes and other resources).
\end{abstract}

Keywords: pensions, reform, financing, sustainability

REFERENCIA NORMALIZADA

Zubiri, I. (2015). "Cómo reformar las reformas de las pensiones... y el coste de no hacerlo". Cuadernos de Relaciones Laborales, Vol. 33, núm. 2, p. 259-287.

SUMARIO: Introducción. 1. Las Reformas Realizadas. 1.1. La Reforma del año 2011. 1.1.1. Elementos de la reforma. 1.1.2. Coste para los pensionistas de la reforma del 2011. 1.2. La Reforma del año 2013. 1.2.1 Elementos de la reforma. 1.2.2. Coste los pensionistas de la reforma a Reforma del 2013. 1.3. Coste total de las reformas. 2. El Nivel sostenible de pensiones. 2.1. Aspectos conceptuales. 2.1.1. Concepción Actuarial. 2.1.2. Concepción Social. 2.2. Los niveles sostenibles de pensiones. 2.2.1. El modelo Actuarial. 2.2.2. El modelo Social. 2.3. Conclusión. 3. El modelo a seguir por las pensiones en España. 4. Los ingresos adicionales del sistema. 4.1. Fiscalidad Comparada. 4.2. Aumentos de las Cotizaciones para financiar pensiones. 4.3. Impuestos. 4.4. Otras formas de financiación. 5. El Futuro del Sistema de Pensiones. 6 Bibliografía. 


\section{Introducción}

En los últimos años en España se han realizado dos reformas sustanciales del sistema de pensiones. El objetivo de estas reformas ha sido garantizar la sostenibilidad del sistema. Esto es, que con los recursos que tiene el sistema se puedan pagar las pensiones que promete el sistema.

Para lograr esta sostenibilidad se podría haber optado por aumentar los ingresos del sistema, reducir los gastos o una combinación de ambas. La opción que han optado ambas reformas ha sido bajar las pensiones y mantener los ingresos. El resultado de ha sido una reducción drástica de las pensiones que ha afectado a la pensión inicial, el número de años durante los que se cobra la pensión y, en última instancia, al valor real de las pensiones que se cobran tras la jubilación. Simplemente, los pensionistas cobrarán una pensión inicial más baja, durante menos tiempo y cuyo valor real ira bajando desde el momento en que se jubilen. Peor aún, la reformas del 2013 ha establecido una regla automática de reducción futura de las pensiones.

Tras esta reforma, el sistema de pensiones español se reduce a poco más que decir, lo que se recaude (a los tipos de cotización vigentes) se repartirá entre los pensionistas en proporción a lo cotizado. Esto acabará conduciendo a una sociedad envejecida y empobrecida en la que la diferencia de renta entre jubilados y activos será mucho mayor que ahora. Y esto ocurrirá en una sociedad que, previsiblemente, dentro de 40 años será mucho más rica que la actual.

Una característica sorprendente de estas reformas es que, a pesar de conllevar reducciones drásticas de las pensiones, se han realizado sin demasiadas protestas de los sindicatos y agentes sociales. Quizá sea porque las reformas se han hecho en medio de una crisis o quizá porque los efectos son de largo plazo. Pero la realidad es que las reformas han sido aceptadas sin casi oposición.

Lo que voy a hacer en este artículo es analizar las reformas realizadas en 2011 y 2013 y sus implicaciones para los pensionistas (Sección 2). A continuación (Sección 3) se determina el nivel de pensiones sostenible según diversos criterios económicos y éticos. La Sección 4 propone un modelo en el que, al contrario que ahora, sean los gastos que se quieren realizar los que determinen los ingresos que se deben obtener. La Sección 5 explora las fuentes adicionales de ingresos para financiar un nuevo modelo de pensiones. Finalmente la 6 , recopila el análisis previo y lo resume en un conjunto de medidas de reforma.

Quizá la idea más importante que se defiende en este trabajo es que, si se desea evitar un empobrecimiento generalizado de los jubilados futuros, se debe pasar de un sistema como el actual en el que los ingresos determinan los gastos a otro en el que sean los gastos los que determinen los ingresos necesarios. 


\section{Las Reformas Realizadas}

El modelo español de pensiones tiene su origen en el Pacto de Toledo de 1995. Este pacto fue un una acuerdo político que establecía las base para reformar el sistema de pensiones en aras a buscar su sostenibilidad. Un elemento importante de este pacto fue la denominada separación de fuentes. Esto es, el principio de que las pensiones contributivas deben financiarse exclusivamente con cotizaciones sociales. En su momento esto parecía una buena idea para dotar al sistema de recursos suficientes ${ }^{1}$. Sin embargo, posteriormente, se ha mostrado como uno de los elementos que ha forzado la reducción de las pensiones. Simplemente, como por razones económicas no se pueden subir de forma sustantiva los tipos de cotización ${ }^{2}$ (y por extensión los ingresos del sistema) la única vía de ajuste que, de facto, ha dejado el Pacto de Toledo ha sido reducir las pensiones.

$\mathrm{Al}$ amparo del Pacto de Toledo se tomaron medidas como incentivar el retraso en la jubilación, indiciar las pensiones con el IPC o aumentar el número de años en la base reguladora. Estas medias, implicaban una reducción moderada de las pensiones pero evidentemente no eran suficientes para garantizar la sostenibilidad del sistema. Sin embargo, la bonanza económica que estaba experimentado España hizo que poco a poco el problema dela sostenibilidad de la pensiones despareciera del primer plano de las discusiones de política económica. En cierta forma se pasó a pensar que la inmigración y el crecimiento serían suficientes para mantener las pensiones.

La crisis económica que comenzó en el año 2008 reavivó el debate sobre las pensiones. Por un lado, las instituciones europeas presionaron para que se redujeran las pensiones en España argumentando que esto era necesario para la sostenibilidad de las finanzas públicas. Por otro, la recaudación por cotizaciones cayó y, a partir del año 2011 el sistema entró en déficit.

El argumento de las instituciones europeas es un tanto sorprendente porque la reforma de las pensiones tendrá, en su caso, efectos significativos en el medio y largo plazo, pero no en el corto plazo. Por tanto, reducir las pensiones no tiene ningún efecto significativo sobre las finanzas públicas en el corto o medio plazo y, por extensión, no sirve de nada como instrumento para salir de la crisis ${ }^{3}$. En todo caso, la presión de la UE y la caída de las cotizaciones han dado lugar a dos reformas del sistema de pensiones. La primera, en el año 2011, modificó (generalmente a la baja) diversos elementos del cómputo de la pensión inicial y la

${ }^{1}$ Esto implicaba que la parte de las cotizaciones que en aquel momento se dedicaba a financiar la sanidad, pasaría a dedicarse a pensiones.

${ }^{2}$ Véase la sección 5.2.

${ }^{3}$ El único argumento, muy cuestionable, para justificar la reducción de las pensiones es que la reducir el gasto en el largo plazo aumente la credibilidad de los inversores en la sostenibilidad a largo plazo de la deuda. 
segunda en el año 2013, en la que se han reducido la pensión inicial (a través del llamado factor de sostenibilidad) y el coeficiente de actualización de las pensiones (a través del factor de revalorización). En ambos casos se han bajado las pensiones sin aportar recursos al sistema.

\subsection{La Reforma del año 2011}

La reforma del año 2011 fue una reducción de las pensiones por dos vías fundamentales. Primero retrasar la edad de jubilación. Segundo, aumentar el número de años incluidos en el cálculo de la pensión lo que, para la mayoría de los pensionistas, reduce la pensión inicial.

\subsubsection{Elementos de la reforma}

La reforma del año 2011, estableció cuatro medidas básicas.

A) Ampliación de la edad legal de jubilación que pasó de los 65 a los 67 años.

No obstante, quien al llegar a los 65 haya cotizado a 38,5 años puede jubilarse con una pensión completa. Esta medida se aplicará de forma progresiva hasta completarse en el 2027.

B) Ampliación del periodo de cálculo de la base reguladora.

Esta medida se aplicará de forma progresiva hasta completarse en el 2022. El número de años que se incluyen en el cálculo de la base reguladora (pensión base) aumenta progresivamente de 15 a 25 años.

C) Linearización de los porcentajes a aplicar sobre la base reguladora en función de los años cotizados y aumento en dos años del periodo necesario para acceder a una pensión completa. Esta medida se aplicará de forma progresiva hasta completarse en el 2027. Consistente con el aumento en dos años de la edad de jubilación, tras la reforma se necesitan dos años más de cotización para acceder a una pensión completa (37 años frente a los 35 anteriores). El mínimo de cotización para tener una pensión sigue siendo de 15 años (que dan derecho a un $50 \%$ de pensión) pero cambia el peso de cada año adicional de cotización (sobre el mínimo). Antes, cada uno de los diez primeros años añadía un 3,5\% de pensión y cada uno los diez restantes aportaban un $2 \%$. Tras la reforma cada año aportará un $1,9 \%$ de pensión.

\section{D) Introducción del denominado Factor de Sostenibilidad}

La reforma establecía que a partir del año 2027, cada 5 años se ajustaran los parámetros del sistema por el aumento de la esperanza de 67 años en el año en que se efectúe la revisión y la esperanza de vida a los 67 años en 2027. El significado concreto de esto era difuso pero, en todo caso, implicaba que a partir del año 2032 se revisarían las pensiones por el aumento en la esperanza de vida. Esto es, a la baja. Este factor ha quedado eliminado por la reforma del 2013 que lo ha precisado, 
adelantado en el tiempo y completado con un segundo factor de corrección (factor de revalorización $)^{4}$.

En suma, la reforma del año 2011 es una reducción de las pensiones para casi todos los ciudadanos que implica que tienen que trabajar más para recibir una pensión completa, tienen una pensión base menor y cobran la pensión durante menos años.

\subsubsection{Coste para los pensionistas de la reforma del 2011}

Las medidas en la reforma reducen las pensiones para la mayoría de los contribuyentes. Por ejemplo, el retraso de la edad de jubilación puede tener un coste de hasta el $10 \%$ de la pensión vitalicia ${ }^{5}$. La linearización puede costar a algunos contribuyentes hasta un 5\% de su pensión ${ }^{6}$. Los efectos de la ampliación de la base son difíciles de determinar con generalidad. El coste promedio puede ser de hasta un $10 \%$ de la pensión, pero hay casos en lo que la pensión puede incluso aumentar? Las implicaciones del factor de sostenibilidad no estaban claras, porque no se especificó como se iba a aplicar. No obstante en la memoria explicativa de la reforma se estimó que la aplicación de este factor podría suponer una reducción adicional (a las demás medidas) de las pensiones de entre un 25\% (en el 2040) y un $50 \%$ (en el 2060).

En todo caso, dejando al margen este factor, la reforma del 2011 no produce un patrón uniforme de pérdidas. Por ejemplo, quien llegue a los 65 años habiendo cotizado 38,5 años puede perder sólo el 10\% de su pensión (por el aumento de años en el cálculo de la base reguladora). La pérdida aumentará a un $20 \%$ si a los 65 se han cotizado entre 35 y 38,5 años (porque la edad de jubilación se retrasará dos años). Por otro lado, la pérdida será del $25 \%$ si se llega a los 67 años con 25 cotizados (por el efecto linerización).

${ }^{4}$ Se tomaron otras medidas de menos alcance como permitir jubilaciones anticipadas, mejorar algunas pensiones mínimas, integrar los regímenes, profundizar en la separación de fuentes y una mejora del funcionamiento de las Mutuas de Accidentes de Trabajo.

${ }^{5}$ No reduce el valor de la pensión anual, pero reduce el número de años durante los que se cobra la pensión. Por ejemplo quien, como el promedio, cobrara la pensión durante 20 años, ha pasado a cobrarla durante 18 con un coste del $10 \%$.

${ }^{6}$ A quienes hayan cotizado en torno a 25 años.

${ }^{7}$ Esto puede ocurrir en algunos casos en los que, previo a la jubilación el trabajador haya estado en paro sin cobertura, pero sin embargo haya trabajado con sueldos significativos en los diez años que se añaden al cálculo de la base reguladora. No parece probable que en la práctica estas condiciones se den en muchos casos. 
La OCDE estima que la reforma del 2011 redujo la pensión mediana (tasa bruta de sustitución) del 81,2 (del salario previo) al $79,3 \%{ }^{8}$. Esto equivale a una reducción del $9 \%$. Esta reducción no incluye, sin embargo, el coste del retraso de la jubilación ni las implicaciones del factor de sostenibilidad. Como ya se ha señalado el retraso de la jubilación supone una reducción de la pensión vitalicia del $10 \%$. Por tanto, incluso sin factor de sostenibilidad la reforma del 2011 supuso una reducción al pensionista mediano de casi un $20 \%$. La mitad porque la baja la pensión anual y la otra mitad porque cobra al pensión menos años.

Otra forma de apreciar a los efectos para los pensionistas de esta reforma es comparar el coste estimado de las pensiones antes y después de la reforma. El Cuadro 1, resume las estimaciones de los efectos de la reforma del 2011 que realizó el gobierno en el programa actualización del plan de estabilidad español 2012-2015'

Cuadro 1. Coste para los pensionistas de la reforma del 2011

\begin{tabular}{|l|c|c|c|c|c|c|}
\hline & $\mathbf{2 0 1 0}$ & $\mathbf{2 0 2 0}$ & $\mathbf{2 0 3 0}$ & $\mathbf{2 0 4 0}$ & $\mathbf{2 0 5 0}$ & $\mathbf{2 0 6 0}$ \\
\hline Gasto pre Reforma & 10,1 & 10,9 & 11,8 & 14,5 & 16,8 & 16,7 \\
Gasto post Reforma sin FS & 10,1 & 10,6 & 10,6 & 12,3 & 14,0 & 13,7 \\
Gasto post Reforma con FS & 10,1 & 10,6 & 10,6 & 12,1 & 13,4 & 13,0 \\
& \multicolumn{7}{|c|}{ Variación absoluta en \% del PIB } \\
Gasto sin FS & 0 & $-0,3$ & $-1,2$ & $-2,2$ & $-2,8$ & $-3,0$ \\
Gasto con FS & 0 & $-0,3$ & $-1,2$ & $-2,4$ & $-3,4$ & $-3,7$ \\
& 0 & \multicolumn{7}{|c|}{ Variación Porcentual } \\
Gasto sin FS & 0 & $-2,8$ & $-11,3$ & $-17,9$ & $-20,0$ & $-21,9$ \\
Gasto con FS & 0 & $-2,8$ & $-11,3$ & $-19,8$ & $-25,4$ & $-28,5$ \\
\hline
\end{tabular}

FS $=$ Factor de Sostenibilidad

Fuente: Actualización del Programa de Estabilidad 2012-2015, Ageing Report (2012)

Este Cuadro confirma la idea de que, una vez la reforma sea plena, (a partir del 2027) la reducción media de las pensiones será de entorno al $20 \%$ sin factor de sostenibilidad y de entre el $25 \%$ y el $30 \%$ con factor de sostenibilidad. Es por tanto una reforma cuyo coste recae totalmente sobre los pensionistas futuros.

\subsection{La Reforma del año 2013}

La reducción de pensiones realizada en el año 2011 no garantizaba la sostenibilidad de largo plazo del sistema. Además por la crisis que comenzó en el 2008, había serios problemas de sostenibilidad incluso en el corto plazo. Por ello, el gobierno realizó en el año 2013 una nueva reforma de las pensiones destinada a restablecer la sostenibilidad del sistema. Esta sostenibilidad no se basa en ningún

\footnotetext{
${ }^{8}$ OCDE (2011).

${ }^{9}$ Reino de España (2011)
} 
aumento de los recursos del sistema, sino, nuevamente, en una reducción de las pensiones que bajan hasta que lo que se gasta se iguale a lo que se ingresa. Para ello, la reforma se ha limitado a establecer dos reglas dos automáticas de reducción de las pensiones. La primera se aplica cuando la población envejece. Y la segunda cuando los gastos son inferiores a los ingresos. De esta forma, la reforma del 2013 reduce aún más unas pensiones que ya se habían reducido con la reforma del 2011.

\subsubsection{Elementos de la reforma}

Los dos factores de corrección de las pensiones que se introducen son:

\section{A) Factor de Sostenibilidad.}

Este factor ajusta por el envejecimiento de la población y da forma concreta al factor de sostenibilidad introducido en la reforma del 2011 y además lo adelanta en el tiempo. A partir del año 2019 las pensiones iniciales se reducirán por el aumento en la esperanza de vida a los 67 años. Lo que ocurre básicamente es que si se espera que el pensionista viva un 5\%, más entonces su pensión inicial se reduce en un 5\%. Obviamente este factor sólo se aplica una vez a cada pensionista (al jubilarse) y afecta a la pensión inicial.

\section{B) Índice de revalorización.}

Hasta ahora las pensiones se revalorizaban según el índice de precios. La reforma del 2013 elimina esto y las pensiones pasan a revalorizarse según un índice que depende de la solvencia financiera del sistema. De forma más precisa, la revalorización anual de las pensiones (su tasa anual de crecimiento) será igual a:

Índice de Revalorización de las pensiones =

Tasa de variación de ingresos (fundamentalmente las cotizaciones)

-tasa variación del número de pensiones contributivas

-tasa variación de la pensión media (efecto sustitución)

-porcentaje $(\alpha)$ de eliminación del déficit del sistema

Inicialmente (primer quinquenio) se establece que la tasa de eliminación $(\alpha)$ del déficit será el $25 \%$. Esto implica, obviamente que tras unos pocos periodos el déficit se eliminará. Por ejemplo en 5 años bajará un $75 \%$ y en 10 un $90 \%$.

Esta fórmula dice que el porcentaje incremento anual de las pensiones es igual al aumento porcentual de los ingresos del sistema (fundamentalmente la recaudación por cotizaciones) menos la tasa de aumento del número de pensiones contributivas (los que se incorporan al sistema menos lo que fallecen en porcentaje de los que hay) menos el aumento de la pensión media (debido a que los que se incorporan tienen pensiones más altas que los que fallecen; el denominado efecto sustitución) menos 
el porcentaje en el que se quiere cerrar el déficit (por unidad de gasto ${ }^{10}$ ) del sistema $^{11}$.

El índice de revalorización simplemente dice una vez que se llegue al equilibrio (entre cotizaciones y pensiones) la pensiones se determinaran repartiendo lo que se recauda en proporción a las aportaciones (y a la esperanza de vida de las generaciones). Mientras haya déficit, parte de lo recaudado se destinará a reducir el déficit.

Dado que las pensiones crecen más rápido que las cotizaciones es claro que, por lo menos, en el corto y medio plazo este índice va a ser negativo. Máxime, cuando se parte de una situación de déficit. Para evitar que el índice sea negativo y las pensiones nominales bajen la Ley establece que se aplicará una revalorización mínima anual del $0,25 \%$. Es decir que si el valor resultante de la fórmula es menor que 0,25 se aplica este último valor. Obviamente esto no evita que las pensiones pierdan capacidad real de compra (siempre que se aplique el mínimo y la inflación sea mayor que el $0,25 \%$ ). Como compensación también se establece una cota superior, según la cual la revalorización máxima anual será igual al IPC más 0,5.

Como se hizo en el 2011, la reforma del año 2013 no dota de ingresos adicionales al sistema y se limita a reducir las pensiones aún más. Más importante establece un mecanismo de ajuste permanente que, en la práctica, implica una reducción constante de las pensiones reales sin necesidad alguna de haya discusiones parlamentarias o votaciones de ningún tipo.

\subsubsection{Coste los pensionistas de la reforma a Reforma del 2013}

Las implicaciones financieras de la reforma están claras. El factor de sostenibilidad afecta exclusivamente a las pensiones iniciales A partir del 2019 irá reduciendo cada vez más las pensiones iniciales (en relación a las que habría sin este factor), la reducción en el año 2060 será de entorno al $10 \%{ }^{12}$, Entre medio se producirá una reducción anual (aproximada) de un $0,25 \%$.

El índice de revalorización afecta a la actualización de las pensiones existentes. En todos los contextos razonables, el índice de revaloración va a crecer durante muchos años por debajo de la inflación. Y en muchos, esto será así durante los

${ }^{10}$ Esto es (Gastos - Ingresos/Gastos)

${ }^{11}$ Para evitar variaciones bruscas coyunturales la aplicación del índice de revalorización se hace utilizando medias de once años (cinco pasados, el presente y cinco estimados en el futuro). En la práctica, este promedio tan amplio tiene mucho que ver con suavizar en los primeros años las implicaciones del modelo sobre las pensiones (porque el sistema tuvo superávit hasta el año 2010).

${ }^{12}$ Según las tablas de la seguridad social, la esperanza de vida a los 67 años pasará de los 19,35 años en el 2019 a 21,32 años en el 2060. Esto equivale a un aumento de la esperanza de vida (reducción de la pensión) del 10,1\%. Cabe señalar que con la propuestas de los expertos, la reducción podría superar el 16\% (Devesa et al (2013)) 
próximos 40 años. Esto implica que, desde que se jubile el pensionista va a perder capacidad adquisitiva. Para evitar que las pensiones nominales bajen (algo que ocurriría si se aplicase el índice de revalorización sin límites), el gobierno ha puesto un crecimiento nominal mínimo del 0,25\%. Esta garantía es, sin embargo, ridícula porque no impide que las pensiones pierdan capacidad adquisitiva. Y cualquier economista sabe, desde el primer día de carrera que lo relevante no son las variables nominales, sino las reales. Y lo mismo pasa con cualquier no economista cuando lo piensa un poco. En realidad el límite del $0,25 \%$ es poco más que un engaño porque pretende trasmitir la idea de que las pensiones no bajarán nunca.

La cuantía de esta reducción depende de cuál sea el crecimiento futuro del PIB. Incluso con una previsión optimista como la del Ageing Report 2012 de la Comisión Europea, la reducción promedio puede ser elevada. Por ejemplo, según la estimación de Rosado y Domínguez (2014), el índice de actualización sería del $0,25 \%$ hasta el año 2023. Después comenzaría a subir, pero hasta el año 2048 permanecería por debajo del $2 \%$, que es la inflación objetivo para la Comisión Europea y la que los autores suponen en su trabajo. Si esto es así, los pensionistas que se jubilen en los próximos 35 años perderán capacidad adquisitiva real ${ }^{13}$ cada uno de estos años. Por tanto los jubilados irán acumulando estas pérdidas y cuantos más años vivan, la pérdida será mayor. El promedio de esta pérdidas (pequeñas al principio y grandes al final) que sufrirá un trabajador está en torno al $15 \%$. En el máximo (el año previo al fallecimiento) superará el $25 \% \mathrm{Si}$ en vez de la pérdida real se analizara la pérdida nominal ${ }^{14}$, las diferencias serían incluso mayores. La pérdida anual promedio se supera el $18 \%$ y en el máximo (justo antes de fallecer) puede llegar a casi el $40 \%{ }^{15}$. Por otro lado hay que tener en cuenta que si como sugiere el Ageing Report del 2015 el crecimiento del PIB es menor que el previsto en el informe del 2012, la reducción puede ser mayor.

El análisis anterior sugiere que el índice de actualización implica:

A) Una reducción de las pensiones nominales (en relación a las que habría si no se aplicara este factor) y de las pensiones reales (en términos absolutos de capacidad adquisitiva). La reducción nominal media puede estar en torno al 18\% y la real en torno al $15 \%$.

B) Un deterioro progresivo de las pensiones nominales (en relación a las que cobraría sin reforma) y reales (en términos absolutos de capacidad adquisitiva) de

${ }^{13}$ La pérdida de capacidad adquisitiva es la diferencia entre los valores reales de las pensiones. Esto es la variación de la cantidad de bienes que se puede comprar con la pensión (pensión/precios.

${ }^{14}$ Diferencia entre la pensión antes de la reforma y después de la reforma.

${ }^{15}$ Los cálculos se han realizado utilizando el índice de actualización obtenido en Rosado y Domínguez (2014), suponiendo una inflación del 2\% y con las esperanzas de vida del INE. 
cada jubilado a medida que se hace más anciano. Esto es, al principio se pierde poco, pero a medida que pasa el tiempo, las pérdidas de van acumulando pudiendo llegar la doble de la media. Una implicación de esto es que los más ancianos van a vivir en una pobreza mayor.

Otra forma de analizar el coste de la reformar para los pensionistas es observar las previsiones mandadas por el gobierno a la Comisión Europea en su Programa de Estabilidad $^{16}$. El Cuadro 2, recoge estos datos.

Cuadro 2. Coste para los pensionistas de la reforma del 2013

\begin{tabular}{|l|c|c|c|c|c|c|}
\hline & $\mathbf{2 0 1 3}$ & $\mathbf{2 0 2 0}$ & $\mathbf{2 0 3 0}$ & $\mathbf{2 0 4 0}$ & $\mathbf{2 0 5 0}$ & $\mathbf{2 0 6 0}$ \\
\hline Gasto Pre Reforma & 11,8 & 12,5 & 13,0 & 14,6 & 15,8 & 13,5 \\
Gasto Post Reforma & 11,8 & 11,8 & 11,2 & 11,9 & 12,3 & 11,0 \\
Variación absoluta & 0,0 & $-0,7$ & $-1,8$ & $-2,7$ & $-3,5$ & $-2,5$ \\
Variación Porcentual & 0,0 & $-5,6$ & $-13,8$ & $-18,5$ & $-22,2$ & $-18,5$ \\
\hline
\end{tabular}

Fuente: Actualización del Programa de Estabilidad 2015-2018, Ageing Report 2015

Tal y como muestra este cuadro, el objetivo de la reforma es mantener el gasto en pensiones estable en torno al 12\% (el mismo nivel que ahora). Lo más sorprendente de este objetivo es que se pretende mantener constante el gasto (en porcentaje del PIB) mientras el porcentaje de población mayor de 65 años casi se duplicará, pasando del $18,1 \%$ en 2014 al $38,17 \%$ en $2060{ }^{17}$. El precio es, evidentemente una reducción drástica de las prestaciones y, por extensión del gasto asociado. Así, en el año 2040 los pensionistas perderán en promedio un $18,5 \%$ de lo que cobraban. Esta cifra aumentará al $22,2 \%$ en el 2050 se reducirá al $18,5 \%$ en el 2060. Como ya se ha señalado, los mayores perderán más que estos promedios y los jubilados recientes menos.

\subsection{Coste total de las reformas}

El análisis anterior sugiere que para la mayoría de los pensionistas la reforma del 2011 supuso un coste de en torno al 19\% (10\% por el alargamiento de la esperanza de vida y $9 \%$ por el resto de medidas). Esta reducción la soportarán la mayoría de los que se jubilen a partir del 2029.

La reforma del 2013 supone un coste de un $0,25 \%$ anual por el efecto envejecimiento (factor de sostenibilidad) que en el largo en el largo plazo (quienes se jubilen en el 2060) se acumulará hasta un 10\%. El factor anual de ajuste reducirá el valor anual real de las pensiones hasta por lo menos el 2048. Esto implica que cuánto más anciana sea una persona menor será su capacidad adquisitiva real. Para

${ }^{16}$ Las cifras de gasto tras la reforma son las mismas que publica la Comisión en su Ageing Report del año 2015.

${ }^{17}$ Cifras del INE. 
un jubilado la reducción promedio puede ser de un 15\%, aunque será poco al principio y quizá el doble de eso al final.

El Cuadro 3, analiza el efecto de las reformas en el coste de las pensiones tal y como lo estima el gobierno en sus programas de estabilidad enviados a la Comisión Europea. Simplemente recopila los resultados de los Cuadros 1 y 2 y sirve para estimar la reducción de la pensión media de jubilación. Obviamente, cuando una reforma se aplica de forma paulatina o tiene efectos de largo plazo, al principio afectará a poco jubilados y el efecto sobre la pensión media será pequeño. Cuando afecta a todos los jubilados (en los últimos años) el efecto sobre la pensión media será más revelador sobre las implicaciones reales de la reforma.

Tal y como muestra este cuadro las reformas han tenido un único objetivo. Llevar el coste de las pensiones a un $13 \%$, que es lo financiable a los niveles actuales de cotización (incluyendo la aportación del estado). Por eso las reformas se han limitado a reducir las pensiones y hacer pagar todo el coste del envejecimiento a las generaciones futuras de pensionistas. Esto es, se han bajado las pensiones en una cuantía igual al aumento futuro que iban a tener por el envejecimiento. Si el coste en el 2013 era el 12\% (del PIB), en el 2050, será el mismo. Y eso a pesar de que el porcentaje de la población pensionista se pueda duplicar.

Cuadro 3. Reducción del Coste de las Pensiones tras las reformas

\begin{tabular}{|l|c|c|c|c|c|}
\hline & $\mathbf{2 0 2 0}$ & $\mathbf{2 0 3 0}$ & $\mathbf{2 0 4 0}$ & $\mathbf{2 0 5 0}$ & $\mathbf{2 0 6 0}$ \\
\hline \multicolumn{7}{|l|}{ Reducción del Gasto en \% del PIB } \\
\hline Reforma 2011 & $-0,3$ & $-1,2$ & $-2,2$ & $-2,8$ & -3 \\
\cline { 2 - 6 } Reforma 2013 & $-0,7$ & $-1,8$ & $-2,7$ & $-3,5$ & $-2,5$ \\
Total & -1 & -3 & $-4,9$ & $-6,3$ & $-5,5$ \\
\hline \% de Reducción del Gasto $^{\mathbf{1}}$ & 7,8 & 21,1 & 29,2 & 33,9 & 33,3 \\
Gasto Final Estimado & 11,8 & 11,2 & 11,9 & 12,3 & 11 \\
\hline
\end{tabular}

1. Las cifras de las reformas no son directamente comparables porque se basan en supuestos poblacionales diferente. Este porcentaje ignora estos problemas de comparabilidad Fuente: Cuadros 1 y 2

El resultado es una reducción sustancial de las pensiones en relación a la los trabajadores hubieran recibido pre reforma. La reducción media es creciente en el tiempo en un proceso que va desde casi el $8 \%$ en el 2020 hasta el $35 \% \%$ en el 2050. Es decir que el ahorro para la seguridad social es sustancial. Y la pedida para los pensionistas de la misma magnitud. Como ya se ha señalado los valores más relevantes son los de los últimos años, cuando la reforma haya producido todo sus efectos y afecta a todos los pensionistas. En el corto plazo la cifra del Cuadro 3, será un promedio entre los que pierdan mucho (porque se les aplica toda la reforma) y los que pierdan poco (porque solo se les aplica una parte de la reforma). En todo caso, el Cuadro 3 sugiere reducciones sustanciales de largo plazo que pueden llegar al $35 \%$ o, incluso, más. 


\section{El Nivel sostenible de pensiones}

Antes de analizar cuáles deben ser las reformas en el sistema español de pensiones es conveniente a determinar cuál es el nivel sostenible de pensiones (cuánto se puede gastar en pensiones) y cuál es el nivel de pensiones que, por razones éticas, se desea (o se debe) mantener. Esto depende, obviamente, de la concepción que se tenga del sistema público de pensiones.

\subsection{Aspectos conceptuales}

Hay dos concepciones básicas del sistema de pensiones, la actuarial y la social. En la primera, los ingresos (mediante cotizaciones) determinan las pensiones posibles. En la segunda las pensiones que se desean mantener son las que determinan los ingresos que debe obtener el sistema (mediante cotizaciones, impuestos $\mathrm{u}$ otros). Ambas concepciones no son equivalentes porque cuando como ocurre en España, las cotizaciones no se pueden aumentar significativamente, el único mecanismo de ajuste del sistema actuarial es la reducción de las pensiones.

\subsubsection{Concepción Actuarial}

El enfoque actuarial presupone que la seguridad social debe actuar como una gran empresa privada de seguros que iguala ingresos (cotizaciones) a gastos (pensiones). Si esto es así, la existencia de una seguridad social pública basada en el reparto solo tiene justificación cuando la rentabilidad que produce, es superior a la que se derivaría de un sistema obligatorio de pensiones privadas.

Con una concepción actuarial de la seguridad social la pensión adecuada es la actuarialmente justa. Una forma de calcular esta pensión sería establecer un tipo de interés de referencia y ajustar en cada momento del tiempo las cotizaciones. Otra, mantener constantes las cotizaciones y repartir lo resultante entre los pensionistas. El primer modelo, sería el equivalente público a un sistema privado de beneficio definido. El segundo, el equivalente a un sistema de contribución definida.

El esquema de prestación definida garantiza unas pensiones futuras adecuadas (en función de la rentabilidad que se garantice) pero plantea varios problemas. Primero, que no hay una base para establecer un tipo de rentabilidad real. Segundo que en contextos de envejecimiento, los aumentos de tipos de cotización necesarios para garantizar a rentabilidad pueden ser muy elevados lo que, en el corto y medio plazo, puede afectar al empleo. Tercero, que todo el riesgo (de que el sistema no sea sostenible y haya que aumentar las cotizaciones) recae sobre las generaciones futuras de trabajadores.

Cuando se opta por mantener los tipos de cotización y ajustar las pensiones, todo el riesgo se traslada a los pensionistas futuros. Lo que se hace es simplemente dividir lo que se recauda (a los tipos vigentes) entre las pensiones a cobrar. Este enfoque presupone que los jubilados futuros no tienen derecho a ningún nivel de pensión. Simplemente, si las cosas van mal, los pensionistas deben aceptar la pensión que resulte, por baja que sea. Dado que las cotizaciones son obligatorias esto equivale a obligarles a realizar una apuesta sin posibilidad de cubrirse. Este 
sistema no garantiza, por supuesto, que las pensiones futuras sean suficientes en ningún sentido.

En un contexto como el actual en el que la población está envejeciendo, el enfoque actuarial aboca a la segunda solución. Es decir a que las pensiones públicas sean como un plan privado de contribución definida (y rentabilidad incierta). Sin embargo, como ya se ha señalado, los sistemas públicos actuariales sólo se pueden justificar si producen más rentabilidad que los sistemas privados. Esto es, una rentabilidad por encima del tipo de interés real de mercado. El envejecimiento de la población cambia esto y hacer que el reparto sea un mal negocio para el trabajador. Pero si es así, se estarán cambiando sobre la marcha las reglas implícitas en las que siempre han basado la capitalización obligatoria. Esto es, que para el trabajador tener un sistema público de pensiones es más rentable que poner su dinero en un sistema privado ${ }^{18}$.

En suma, por tanto, en contexto de envejecimiento el enfoque actuarial no puede garantizar que las pensiones sean suficientes y contradice uno de los argumentos convencionales para justificar los sistemas públicos de reparto: Que son más rentables que los sistemas privados.

\subsubsection{Concepción Social}

Para muchos el objetivo de la seguridad social no debe ser actuar como una empresa privada de seguros sino garantizar determinados niveles de bienestar en la jubilación. Las cotizaciones son los pagos anticipados por los niveles de bienestar que el Estado les garantiza en la jubilación. El nivel que se garantiza es una cuestión que se debe determinar de forma colectiva. Un nivel mínimo de provisión razonable es suponer que cada trabajador tiene derecho cuando se jubile a unas prestaciones similares a las que él está pagado hoy (con sus cotizaciones) a los jubilados actuales. Simplemente cada trabajador tiene derecho a esperar (y en la práctica probablemente espera) prestaciones, por lo menos, similares a las de los jubilados actuales. Este argumento muchas veces se formula como la existencia de un contrato implícito entre generaciones por el cual cada generación joven paga a sus jubilados pensione similares a las que ellos pagaron. Obviamente una prestación similar significa que es posible realizar ajustes en los niveles de prestaciones siempre que por alguna razón (alargamiento de la esperanza de vida, por ejemplo) haya una tendencia a que estas prestaciones aumenten. Pero, al mismo tiempo, limita la magnitud de los recortes admisibles.

${ }^{18}$ El sector privado puede garantizar sin riesgo una rentabilidad igual al tipo de interés de mercado. 


\subsection{Los niveles sostenibles de pensiones}

Cada concepción de las pensiones da lugar a niveles de pensiones sostenibles diferentes.

\subsubsection{El modelo Actuarial}

El modelo actual de pensiones es España es actuarial. Todas las prestaciones contributivas se financian con cotizaciones y se busca una proporcionalidad entre la pensión que se recibe y las cotizaciones aportadas. Más aún como explicita el propio pacto de Toledo las cotizaciones sociales (al menos las empresariales) no deben aumentar. Si algo, cuando se pueda, deben reducirse.

Limitar los ingresos a las cotizaciones y no subir los tipos tiene implicaciones sustanciales para el sistema de pensiones. Para verlas, el Gráfico 1 analiza la evolución de la recaudación por cotizaciones en España (en \% del PIB) desde 1965. Como pone de manifiesto este Gráfico, desde hace más de cuarenta años la recaudación ha permanecido esencialmente estable en torno al $11,5 \%$. Y esto ha sido así a pesar de que en España el número de empleos ha variado sustancialmente. Simplemente, la recaudación ha sido casi la misma con casi 20 millones de empleos (en 2007) que con 16 millones (2010 y 2013) o incluso con 13 millones (1990) o menos de 12 (1980).

Para ver la razón de esta constancia, hay que recordar que la recaudación como porcentaje del PIB es:

$$
\begin{aligned}
\text { Recaudación } & =\text { Tipo impositivo X }(\text { Renta salariales/PIB }) \\
& =\text { tipo X participación de la rentas salariales en el PIB } .
\end{aligned}
$$

Como el tipo ha permanecido esencialmente constante desde hace más de treinta años ${ }^{19}$, la constancia de la recaudación se debe a que, en lo esencial, la participación de los salarios en el PIB ha sido constante. Simplemente cuando se crea más empleo aumenta la recaudación en euros, pero también crece el PIB (porque las rentas no salariales crecen a la misma tasa que las salariales). Como resultado el cociente recaudación/PIB permanece constante.

La Contabilidad Nacional de España pone de manifiesto que, la participación de los salarios en el PIB, aunque no es contante, ha cambiado muy poco en los últimos 30 años ${ }^{20}$. Esta constancia de la participación de las rentas salariales, no es específica de España. Se produce en la mayoría de los países avanzados. De hecho la Comisión ${ }^{21}$ basa sus estimaciones sobre la evolución de las pensiones en el

${ }^{19}$ Desde comienzo de los 80 el tipo total de cotización se ha mantenido casi siempre entre el 36\% y el 37\%

${ }^{20}$ Véase, por ejemplo, Zubiri (2012)

${ }^{21}$ Comisión Europea (2014) 
supuesto de que la participación de los salarios en la renta es constante ${ }^{22}$. Conviene señalar no obstante, que hay quien cuestiona esta idea y considera que las participación rentas del trabajo en la renta está disminuyendo desde hace varias décadas ${ }^{23}$.

En todo caso, si aceptamos que, en el futuro, en el mejor de los casos, la participación de las rentas salariales el PIB va a permanecer constante (y en el peor va a bajar), con tipo constates, la recaudación por cotizaciones va a permanecer también constante en torno a un 11,5\% del PIB. Dado que alrededor del $85 \%$ de las cotizaciones se dedican a la seguridad social (para pagar prestaciones contributivas), el gasto en pensiones financiable con cotizaciones estaría, en el mejor de los casos, en torno al $10 \%{ }^{24}$.Probablemente menos. La Comisión europea, en su informe del año 2015, sobre el coste del envejecimiento considera que la recaudación por cotizaciones para pensiones permanecerá contante durante todo el tiempo de la proyección (2012-2060) en torno al 10\% del PIB. Eso suplementado con dos puntos del PIB de aportaciones públicas (para complementos a mínimos, pensiones no contributivas, públicas, etc.) sitúa el máximo financiable para la comisión en todo tipo de pensiones, en 12 puntos del PIB.

${ }^{22}$ Obsérvese que la función de producción Cobb-Douglas, que es la que se utiliza en la muchas estimaciones empíricas, solo es válida cuando la participación de las rentas factoriales en la renta total es constante.

${ }^{23}$ Véase, por ejemplo, Karabarbouni y Neiman (2014).

${ }^{24}$ Hay que tener en cuenta que parte de las cotizaciones deben ir a pagar prestaciones contributivas diferentes a las pensiones. 
Gráfico 1. Evolución de la recaudación por cotizaciones (en \% del PIB)

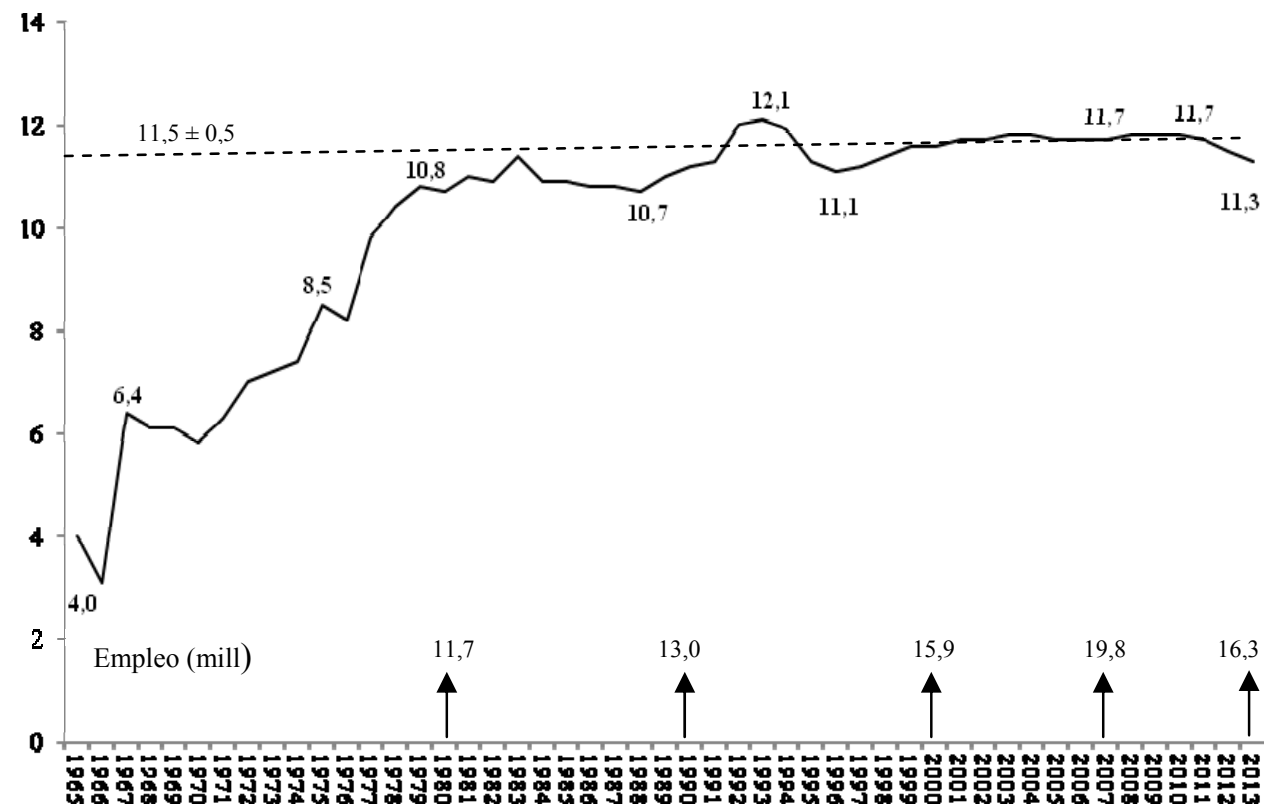

Fuente: ODCE statistics

Tomando todo en cuenta, con el modelo actual de financiación, parece razonable suponer que como mucho se podrán sostener pensiones contributivas de en torno el $10 \%$ del PIB. Dado que el gasto en actual en pensiones ya está a ese nivel, la implicación es que los aumentos futuros de pensiones deben eliminare. Esto es, que las pensiones individuales deben reducirse de tal forma que, a pesar del envejecimiento, el gasto total no aumente. Como ya se ha visto, esto es exactamente lo que han hecho las reformas de las pensiones. Reducir las prestaciones hasta el punto en el que se espera que el gasto total en pensiones no suba.

Obviamente, los ingresos por cotizaciones dedicados a pensiones pueden aumentarse en el futuro por una de dos vías. Primero, aumentado los tipos de cotización (del trabajador, del empresario o de ambos). Segundo, si la tasa de paro baja sustancialmente, trasladando pensiones parte de las cotizaciones que hoy se dedican a desempleo. Estas opciones se exploran en la sección 5.2.

\subsubsection{El modelo Social}

¿Cuál es la capacidad de la economía española para financiar pensiones? Esta cuestión no tiene una respuesta única porque todo depende de la perspectiva desde la que se responda. Una forma de hacerlo es comparar lo que se gastan en la actualidad España y otros países en tanto en pensiones como en otras actividades. El Cuadro 4, explora esta cuestión y para ello recoge algunos indicadores de la 
actividad pública. Como el año 2013 está aún afectado por una crisis severa, las cifras se ofrecen para este año y para el promedio desde el 2002. A efectos indicativos cabe señalar que, según los supuestos que se usan para estimar las pensiones, en el año 2060 España tendrá una renta per cápita que es un $90 \%$ más alta que la actual. Esto implica que cuando España tenga que pagar las pensiones más altas su nivel de renta será superior al que hoy tienen Alemania y Francia y similar al que hoy tienen los EE.UU.

España es uno de los países que menos gasta de la UE15. En el año 2013 su gasto estaba 6 puntos del PIB por debajo del promedio de la UE y en el promedio de los doce último años la cifra ha sido incluso algo superior (6,5 puntos). La diferencia con los países que más gastan (ingresan) es de más de 10 puntos del PIB. En el 2015 sólo tres países gastan igual o menos que España (Alemania, Irlanda y Luxemburgo) y en el promedio de los últimos doce años sólo Irlanda ha gastado menos.

Cuadro 4. Indicadores de Sostenibilidad de las Pensiones en España

\begin{tabular}{|l|c|c|c|c|c|c|c|}
\hline & \multicolumn{2}{|c|}{ Gasto Público } & \multicolumn{2}{|c|}{ Ingresos Públicos } & \multicolumn{3}{|c|}{ Pensiones $^{\mathbf{1}}$} \\
\cline { 2 - 8 } & $\mathbf{2 0 1 3}$ & $\begin{array}{c}\text { Media } \\
\mathbf{2 0 0 2 - 1 3}\end{array}$ & $\mathbf{2 0 1 3}$ & $\begin{array}{c}\text { Media } \\
\mathbf{2 0 0 2 - 1 3}\end{array}$ & $\mathbf{2 0 1 5}$ & Máximo & Media \\
\hline Bélgica & 54,4 & 50,9 & 51,5 & 48,8 & 11,8 & 15,2 & 14,4 \\
\hline Dinamarca & 56,7 & 53,9 & 55,9 & 54,6 & 10,3 & 10,3 & 8,2 \\
\hline Alemania & 44,3 & 45,5 & 44,5 & 43,5 & 10,0 & 12,7 & 11,7 \\
\hline Irlanda & 40,5 & 40,6 & 34,8 & 34,5 & 7,4 & 10,2 & 9,1 \\
\hline Grecia & $59,2^{2}$ & 51,92 & 47,0 & 41,9 & 16,2 & 16,2 & 14,6 \\
\hline España & 44,3 & $\mathbf{4 1 , 7}$ & $\mathbf{3 7 , 5}$ & $\mathbf{3 7 , 8}$ & $\mathbf{1 1 , 8}$ & $\mathbf{1 2 , 5}$ & $\mathbf{1 1 , 7}$ \\
\hline Francia & 57,1 & 54,3 & 53,0 & 50,1 & 14,9 & 14,9 & 13,8 \\
\hline Italia & 50,5 & 48,4 & 47,7 & 45,0 & 15,7 & 15,8 & 15,2 \\
\hline Luxemburgo & 43,8 & 42,0 & 44,5 & 42,9 & 9,4 & 13,4 & 11,9 \\
\hline Holanda & 46,8 & 45,3 & 44,5 & 43,0 & 6,9 & 8,3 & 7,8 \\
\hline Austria & 50,9 & 51,2 & 49,5 & 48,6 & 13,9 & 14,7 & 14,4 \\
\hline Portugal & 50,1 & 47,3 & 45,2 & 41,5 & 13,8 & 15,0 & 14,4 \\
\hline Finlandia & 57,8 & 51,5 & 55,4 & 52,6 & 12,9 & 15,0 & 13,7 \\
\hline Suecia & 53,3 & 52,3 & 51,9 & 52,6 & 8,9 & 8,9 & 7,8 \\
\hline Reino Unido & 45,5 & 44,7 & 39,7 & 39,2 & 7,7 & 8,4 & 8,0 \\
\hline UE15 & 50,3 & $\mathbf{4 8 , 1}$ & $\mathbf{4 6 , 8}$ & $\mathbf{4 5 , 1}$ & $\mathbf{1 1 , 4}$ & $\mathbf{1 2 , 8}$ & $\mathbf{1 1 , 8}$ \\
\hline
\end{tabular}

1. Estimaciones de la Comisión Europea antes de la reforma del 2013. 2. Media 2006-13

Fuentes: Eurostat para gastos e ingresos y Comisión Europea (2015) para pensiones

En los ingresos públicos, las diferencias son incluso más amplias que en el gasto. En 2013 España ingresó 9,3 puntos menos que la media de la UE15 y en el promedio 2002-13, 7,3 puntos menos. El único país que ingresa menos que España (tanto en 2013 como el promedio) es Irlanda. Hay cinco países (Francia, Suecia, 
Bélgica, Dinamarca y Finlandia) países que en 2013 recaudan casi 15 puntos más que España.

El Cuadro 4 presenta también los datos del gasto en pensiones estimados por la Comisión Europea tras de la reforma del 2013. Según estas estimaciones, el gasto en pensiones en España es, y será, muy similar al promedio de la UE15. En el 2013, está 0,4 puntos por encima, pero en la media del periodo 2013-2060 está 0,1 puntos por debajo. El máximo de este periodo está 0,3 puntos por debajo del promedio. En la UE15 hay 8 países con un promedio (en el periodo 2013-60) superior al de España y cuyo gasto máximo estimado es superior al de España. El gasto máximo de España estimado por la UE, el 12,5\% (que se produce en el año 2050) es inferior a lo que hoy se gastan en pensiones países como Grecia, Francia, Italia, Austria o Portugal. España debería pagar estas pensiones cuando sea significativamente más rica que lo que hoy son estos países.

Tomando todo en cuenta, parece claro que, desde un punto de vista económico, España podría soportar económicamente sin grandes esfuerzos incluso un nivel de pensiones del $15 \%$. Esto equivale a un $30 \%$ de lo que se deriva de la última reforma. En realidad, si se desea, incluso se podría ir más algo allí del $15 \%$ sin que esto supusiera un coste inasumible.

\subsection{Conclusión}

La perspectiva actuarial en la que se basa el sistema actual de pensiones, sugiere que el nivel sostenible de pensiones contributivas está en torno al 10\% del PIB. Esto implica, como se ha hecho en las reformas del 2011 y del 2013, una reducción drástica de las prestaciones. Frente a esto, el enfoque económico sugiere que España podría sostener sin problemas pensiones de hasta el 15\%. Obviamente, esto implicaría financiar las pensiones, además de con cotizaciones, con otros ingresos del Estado; fundamentalmente impuestos.

El enfoque actuarial presupone que los ingresos deben determinar los gastos. El enfoque económico que son los gastos los que deben determinar los ingresos del sistema (al menos mientras esos gastos no superen ampliamente el 15\% del PIB). Este enfoque económico es consistente con una concepción social de las pensiones, según la cual los trabajadores tienen derecho a recibir un determinado nivel de prestaciones y el Estado tiene la obligación de financiar este nivel de prestaciones.

\section{El modelo a seguir por las pensiones en España}

En España, a raíz de la aprobación de Toledo, se ha ido afianzando la concepción actuarial de las pensiones. Esto es un tanto sorprende porque tanto en España en el pasado como en la actualidad en muchos países, parte de las pensiones 
se pagan con impuestos ${ }^{25}$. Si a esto se añade que las cotizaciones ni se quieren ni, probablemente, se pueden aumentar demasiado, el único mecanismo de ajuste para hacer frente al envejecimiento es bajar las pensiones. Y esto es, precisamente, lo que han hecho las reformas del 2011 y del 2013. El resultado ha sido bajar las pensiones futuras muy debajo de los niveles económicamente sostenibles y de los que actualmente tienen y en el futuro tendrán otros países.

Frente a esto, la opción es adoptar el modelo social de las pensiones. El Estado es garante de unos determinados niveles de prestaciones (sostenibles económicamente) que si no puede financiar con cotizaciones financiará con otros ingresos. En mi opinión, ese nivel garantizado deben ser unas pensiones similares a las que los jubilados ayudaron a pagar cuando estaban activos. Esta opción es igual de viable económicamente que la opción actuarial y, por tanto, al final la elección entre ambas es política

\section{Los ingresos adicionales del sistema}

La cuestión clave para pasar de un modelo determinado por los ingresos (en el que se ajusta sólo los gastos) a otro en el que la variable determinante sean los gastos (y se ajusten los ingresos) es de dónde deben provenir estos ingresos adicionales. Y en principio pueden venir de impuestos, aumentos en tipos de cotización y otros ingresos (Deuda por ejemplo).

\subsection{Fiscalidad Comparada}

En principio, los ingresos adicionales del sistema deben provenir de impuestos o cotizaciones. El Cuadro 5 ofrece algunos datos comparativos de recaudación de España y otros países de la UE en el año 2013 y en la media de los últimos 12 años. Este cuadro pone de manifiesto, en primer lugar, que desde la perspectiva internacional comparada hay un amplio margen para recaudar más por impuestos generales (IRPF, IVA, Sociedades, etc). No es sólo que España esté casi 6,7 puntos del PIB por debajo del promedio de la UE15 (casi 6 en el promedio de los últimos a12 años). Es que España es uno de los países que menos recauda. Por debajo de Grecia, Portugal o, incluso, Eslovenia y Hungría. La reforma fiscal que ha realizado en el 2015 conlleva una bajada de tipos que, lejos de reducir estas diferencias, las incrementarán.

${ }^{25}$ Véase por ejemplo Zubiri (2013) 
Cuadro 5. Impuestos en España y en la UE (en porcentaje del PIB)

\begin{tabular}{|c|c|c|c|c|c|c|c|c|c|c|}
\hline & \multirow{2}{*}{\multicolumn{2}{|c|}{$\begin{array}{c}\text { Impuestos } \\
\text { (sin Cotiza- } \\
\text { ciones) }\end{array}$}} & \multicolumn{8}{|c|}{ Cotizaciones Sociales } \\
\hline & & & \multicolumn{2}{|c|}{ Totales $^{1}$} & \multicolumn{2}{|c|}{$\begin{array}{c}\text { Empresario } \\
\text { (A) }\end{array}$} & \multicolumn{2}{|c|}{$\begin{array}{c}\text { Trabajador } \\
\text { (B) }\end{array}$} & \multicolumn{2}{|c|}{$\mathbf{A} /(\mathbf{A}+\mathbf{B})$} \\
\hline & 2013 & $\mathrm{Md}^{3}$ & 2013 & $\mathrm{Md}^{3}$ & 2013 & $\mathrm{Md}^{3}$ & 2013 & $\mathrm{Md}^{3}$ & 2013 & $\mathrm{Md}^{3}$ \\
\hline Austria & 27,9 & 27,3 & 14,6 & 14,1 & 6,8 & 6,6 & 5,9 & 5,7 & 53,5 & 53,6 \\
\hline Bélgica & 30,4 & 29,5 & 14,2 & 13,7 & 8,7 & 8,3 & 4,2 & 4,2 & 67,4 & 66,6 \\
\hline Dinamarca & 47,8 & 46,4 & 0,8 & 1,0 & 0,0 & 0,0 & 0,8 & 1,0 & 0,0 & 1,7 \\
\hline Finlandia & 31,3 & 30,3 & 12,7 & 11,8 & 8,9 & 8,7 & 2,9 & 2,3 & 75,4 & 78,8 \\
\hline Francia & 28,2 & 26,6 & 16,8 & 16,0 & 11,3 & 10,9 & 4,1 & 4,0 & 73,4 & 73,3 \\
\hline Alemania & 22,7 & 21,5 & 14,0 & 13,6 & 6,6 & 6,5 & 6,2 & 6,0 & 51,6 & 52,1 \\
\hline Grecia & 22,9 & 20,7 & 10,6 & 10,7 & 4,8 & 4,9 & 4,5 & 4,2 & 51,6 & 54,0 \\
\hline Irlanda & 23,9 & 24,2 & 4,4 & 4,1 & 3,0 & 2,9 & 1,1 & 1,0 & 73,2 & 73,6 \\
\hline Italia & 29,6 & 28,5 & 13,0 & 12,5 & 8,9 & 8,6 & 2,3 & 2,3 & 79,5 & 79,3 \\
\hline Luxemburgo & 28,0 & 27,1 & 11,3 & 10,8 & 4,9 & 4,7 & 5,1 & 4,9 & 49,0 & 49,0 \\
\hline Holanda $^{2}$ & 21,3 & 22,6 & 15,0 & 13,3 & 5,1 & 4,4 & 6,5 & 6,0 & 44,0 & 42,3 \\
\hline Portugal & 24,5 & 22,4 & 8,9 & 8,5 & 5,2 & 4,8 & 3,4 & 3,3 & 60,5 & 59,1 \\
\hline España & 21,3 & 21,4 & 11,3 & 11,7 & 7,8 & 8,3 & 1,7 & 1,8 & 82,1 & 82,0 \\
\hline Suecia & 33,0 & 33,0 & 9,8 & 11,4 & 7,2 & 8,7 & 2,7 & 2,6 & 72,7 & 77,1 \\
\hline Reino Unido & 26,7 & 27,1 & 6,2 & 6,3 & 3,6 & 3,6 & 2,4 & 2,5 & 60,0 & 58,7 \\
\hline UE15 & 28,0 & 27,2 & 10,9 & 10,6 & 6,2 & 6,1 & 3,6 & 3,4 & 59,6 & 60,1 \\
\hline $\begin{array}{l}\text { España- } \\
\text { UE15 }\end{array}$ & $-6,7$ & $-5,8$ & 0,4 & 1,1 & $\overline{1,6}$ & 2,2 & $-1,9$ & $-1,6$ & 22,5 & 21,9 \\
\hline Rep. Checa & 19,3 & 19,0 & 14,8 & 14,7 & 9,4 & 9,3 & 3,0 & 3,2 & 75,8 & 74,6 \\
\hline Estonia & 20,7 & 20,5 & 11,1 & 11,2 & 10,4 & 10,6 & 0,6 & 0,4 & 94,5 & 96,0 \\
\hline Hungría & 26,0 & 25,9 & 12,9 & 12,1 & 4,8 & 7,8 & 7,8 & 4,0 & 38,1 & 66,2 \\
\hline Polonia $^{2}$ & 20,0 & 20,7 & 12,1 & 11,9 & 4,9 & 4,9 & 4,8 & 4,7 & 50,5 & 50,8 \\
\hline Eslovaquia & 16,3 & 17,1 & 13,3 & 12,5 & 7,5 & 7,0 & 3,0 & 2,9 & 71,4 & 70,9 \\
\hline Eslovenia & 22,0 & 22,7 & 14,8 & 14,2 & 5,7 & 5,5 & 7,4 & 7,4 & 43,5 & 42,5 \\
\hline UE21 & 25,9 & 25,5 & 11,6 & 11,2 & 6,5 & 6,5 & 3,8 & 3,5 & 60,4 & 62,0 \\
\hline $\begin{array}{l}\text { España- } \\
\text { UE21 }\end{array}$ & $-4,6$ & $-4,0$ & $-0,3$ & 0,4 & 1,3 & 1,8 & $-2,1$ & $-1,7$ & 21,7 & 20,0 \\
\hline
\end{tabular}

1. Incluye las de empresarios, trabajadores, autónomos y parados. 2. Datos del 2012.

3 Media 2001-2013.

Fuente: OCDE

En el ámbito de las cotizaciones, los márgenes de aumento son menores y están más en las cotizaciones a cargo del trabajador que las que son a cargo del empresario. España es uno de los países donde los trabajadores soportan menores cotizaciones (1,6 puntos del PIB menos que el promedio de la UE15). En cuanto a los empresarios, españoles sus cotizaciones están entre las más altas de la UE $(2,2$ puntos del PIB por encima de la media). Hay que tener en cuenta, no obstante, que hay países en los que los convenios laborales conllevan que las empresas paguen beneficios sociales a sus trabajadores (pensiones privadas o prestaciones médicas). Esto ocurre, por ejemplo, en Holanda o Dinamarca. En todo caso, a pesar de esto, parece razonable aceptar que comparativos con otros países, los márgenes de subida de las cotizaciones empresariales son limitados.

Cabe señalar que, como muestra el cuadro5, los empresarios españoles son los que soportan un mayor porcentaje de la cotización total. Así, mientras que en, por 
ejemplo, Austria y Alemania la distribución de cotizaciones entre trabajadores y empresarios es casi paritaria, en España los empresarios soportan más del 80\% de la cotización.

\subsection{Aumentos de las Cotizaciones para financiar pensiones}

Hay tres vías para aumentar las cotizaciones dedicadas a pensiones. Primero, en el medio plazo, trasladar cotizaciones de desempleo a pensiones. Segundo, subir los tipos de cotización. Tercero, eliminando los topes actuales de cotización.

En cuanto a la primera vía si, como sugieren todas las predicciones, en le medio plazo disminuye la población activa, el paro bajará y se podrían pasar cotizaciones de desempleo a pensiones. Actualmente casi el $15 \%$ de las cotizaciones se dedica a desempleo. Sobre una recaudación de entorno al 11,5\% del PIB, si se pasara la mitad de las prestaciones por desempleo a pensiones esto aportaría casi un punto del PIB al sistema. Pero, para ello, el paro tendía que bajar a niveles por debajo del $10 \%$.

A los tipos actuales, cada punto adicional de cotización supondría ingresos adicionales de 0,3 puntos del PIB. Para explorar la posibilidad de subir los tipos de cotización, el Cuadro 6 resume cuánto representan en los países de la UE 15.

Como muestra este Cuadro, en España la aportación de los trabajadores es sustancialmente más baja que en otro países. Esto abre la posibilidad de si, necesario, aumentar las cotizaciones de los trabajadores. El problema de esta solución es doble.

Cuadro 6. Tipos de Cotización a la Seguridad Social (2014)

\begin{tabular}{|l|c|c|c|c|}
\hline & Empresario & Trabajador & Estado $^{1}$ & \% Empresario \\
\hline Austria & 19,30 & 17,00 & & 53,2 \\
\hline Bélgica & 13,07 & 24,77 & & 34,5 \\
\hline Dinamarca & 0,00 & 8,00 & & 0,0 \\
\hline Finlandia & 22,59 & 6,89 & & 76,6 \\
\hline Francia & 30,50 & 9,95 & & 75,4 \\
\hline Alemania & 18,25 & 19,15 & & 48,8 \\
\hline Grecia & 22,6 & 12,05 & & 65,2 \\
\hline Irlanda & 10,75 & 4,00 & & 72,9 \\
\hline Italia & 28,80 & 8,40 & & 77,5 \\
\hline Luxemburgo & 11,10 & 11,10 & 8 & 50,0 \\
\hline Holanda & 17,30 & 18,50 & & 48,3 \\
\hline Portugal & 23,25 & 11,00 & & 67,9 \\
\hline España & $\mathbf{2 9 , 1 0}$ & $\mathbf{6 , 2 5}$ & & $\mathbf{8 2 , 3}$ \\
\hline Suecia & 21,20 & 0,00 & 7 & 100 \\
\hline Reino Unido & $13,8^{3}$ & $12-2^{2}$ & & 53,5 \\
\hline UE15 & $\mathbf{1 8 , 7 7}$ & $\mathbf{1 0 , 4 7}$ & & $\mathbf{6 0 , 4}$ \\
\hline
\end{tabular}

1. El estado aporta recursos al sistema de forma periódica. 2. 12\% de los ingresos entre 153 y 805 libras y $2 \%$ por encima de 805 libras. 2. Aplicable a ingresos superiores 153 libras/semana

Fuente: Presupuesto de la Seguridad Social 2015 
A) Primero, que es posible que, como sugieren diversos estudios, los trabajadores estén ya soportando (vía salarios más bajos) no sólo sus cotizaciones sino también las de los empresarios. Por ejemplo, González Páramo y Melguizo (2009) tras revisar la evidencia de 45 estimaciones empíricas sobre la incidencia de las cotizaciones concluyen que en las economías continentales-mediterráneas y anglosajonas, los trabajadores soportan en el largo plazo $2 / 3$ de las cotizaciones mientras que en las nórdicas soportan $100 \%$ de las cotizaciones ${ }^{26}$.

$B$ ) Segundo, porque incluso si hoy fuera una solución viable, no está claro que en el futuro lo siga siendo. En el futuro la relación ocupados/pensionistas se reducirá notablemente. Aumentar los impuestos sobre una población trabajadora que ya tiene que financiar a una población jubilada muy amplia, puede no ser viable social o económicamente.

La otra vía para aumentar los ingresos por cotizaciones sería aumentar las cotizaciones empresariales. Estos aumentos, pueden ser criticados en base a dos tipos de argumentos. Primero, como muestra el Cuadro 6, que las cotizaciones actuales ya están entre las más altas de la UE. Segundo, que aumentar las cotizaciones reduce la creación de empleo y la competitividad.

La primera afirmación sólo es parcialmente cierta porque, como ya se ha señalado, ignora que en muchos países dentro y fuera de la UE las empresas, además de las cotizaciones para financiar la protección social pública, tienen que pagar, obligatoria o voluntariamente (vía negociación colectiva) el coste de ciertas prestaciones privadas (pensiones privadas o cobertura médica).

Por otro lado, no está claro que las cotizaciones tengan efectos en el largo plazo sobre el empleo y la competitividad porque, como ya se ha señalado, en el largo plazo es probable que sean los trabajadores quienes soportan la parte más importante de las cotizaciones (vía salarios más bajos). Puede, no obstante, haber efectos de corto y medio plazo. Simplemente, si los empresarios soportan las cotizaciones en el corto y medio plazo, aumentarlas dará lugar a costes salariales mayores y en determinados contextos, esto puede reducir el empleo temporalmente o incluso permanentemente ${ }^{27}$. En una situación de paro como la de España esto puede ser inaceptable.

Finalmente la tercera forma de aumentar la recaudación por cotizaciones sería destopándola. Esto es, quintando el límite superior a la base de cotización que existe actualmente. Este aumento de la base no debería ir acompañada de un aumento de

${ }^{26}$ Dividen su análisis entre estos tres grupos de países para tomar en cuenta el hecho de que la incidencia de las cotizaciones depende del diseño institucional de los países, la forma de negociación salarial, el poder de los sindicatos, leyes de salario mínimo, etc.

${ }^{27}$ Esto puede ocurrir, por ejemplo, en el caso de los trabajadores poco cualificados porque a veces, debido a las leyes de salarios mínimos, no loe empresarios no les pueden trasladar las cotizaciones siquiera en el largo plazo. 
las prestaciones futuras. De esta forma se lograría aumentar los ingresos y hacer el sistema de pensiones más progresivo ${ }^{28} \sin$ aumentos futuros en el coste de la pensiones.

En todo caso hay que apresurarse a señalar que salvo que sean muy grandes, los aumentos de cotizaciones difícilmente van a restablecer el equilibrio financiero del sistema. Si la participación del trabajo en el PIB permanece constante, cada punto del PIB de aumento del gasto en pensiones requeriría casi 3,5 puntos adicionales de tipo de cotización. Cuatro puntos adicionales del PIB requerirían, por tanto, casi 15 puntos adicionales de tipo cotización. Si la participación en el PIB del trabajo disminuyera, el aumento necesario sería incluso mucho mayor.

Tomando todo en cuenta, las cotizaciones adicionales pueden contribuir al mantenimiento de las pensiones por varias vías. En el corto y medio plazo subiendo moderadamente las cotizaciones, especialmente, a cargo del trabajador y, en su caso, destopando la base máxima de cotización. En el largo plazo trasladando cotizaciones del desempleo a pensiones. No es posible, sin embargo, que estos aumentos sean suficientes para garantizar la solvencia del sistema.

\subsection{Impuestos}

La concepción actuarial de las pensiones excluye la utilización de impuestos para financiar las pensiones. Sin embargo, el principio de que las pensiones deben financiarse sólo con cotizaciones no es ninguna inevitabilidad económica. Sólo es una posición ideológica que, además, es contraria a la experiencia pasada de España y a mucho de la experiencia internacional.

Aun nivel conceptual la concepción Social de las pensiones legitima el uso de impuestos para financiar las pensiones porque es la forma de respetar los derechos individuales. Si los niveles de pensiones que colectivamente se determinen no pueden ser alcanzados exclusivamente mediante las cotizaciones, el estado provea los recursos necesarios mediante la aportación de ingresos generales.

Junto a esta, hay otras razones que legitiman el uso de impuestos para pagar pensiones:

A) Cuando una persona cotiza en sus años activos lo hace en la confianza de que cuando esté jubilada recibirá unas prestaciones equivalentes a las que él está pagando a los actuales pensionistas. Si los recursos obtenidos mediante cotizaciones no son suficientes para satisfacer los términos de este contrato implícito prestaciones futuras, por lo menos similares a las que él está ayudando a pagarexiste una base para que el sector público aporte los fondos necesarios de otras fuentes de ingresos.

${ }^{28}$ Sería una redistribución entre rentas del trabajo. Evidentemente sería mejor una progresividad que incluyera a las rentas del capital. Esto implicaría una financiación adicional mediante impuestos. 
B) Si fueran ciertas algunas estimaciones que se han realizado, la participación de las rentas salariales en el PIB va a disminuir de forma importante en el futuro. Dado esto, parece legítimo que la base de sostenimiento de las pensiones se ampliara más allá de las rentas salariales. Simplemente, si la las rentas del capital tienen una participación creciente en el PIB es legítimo que también aumentaran su contribución financiar determinados objetivos del estado del bienestar. Máxime cuando nadie parece dudar que la PIB per capita, aumentará.

C) Buena parte de las rentas de las generaciones futuras se deriva de gastos que han realizado las generaciones presentes y que se les han transmitido sin coste (la educación, la tecnología y buena parte de las infraestructuras de cada generación han sido pagadas por las generaciones precedentes). En este contexto, que las generaciones futuras contribuyan con impuestos a financiar las pensiones es, incluso, equitativo inter generacionalmente.

Más allá de cuestiones conceptuales cabe señalar que ni la evolución pasada del sistema de pensiones en España ni la experiencia internacional comparada avalan el principio de que las pensiones deben financiarse exclusivamente con cotizaciones. En España, por ejemplo, hasta la aprobación del Pacto de Toledo en 1995 nunca se había buscado un equilibrio entre pensiones y cotizaciones. De hecho, antes de la creación del Fondo de Reserva de la Seguridad Social en el año 2000, los superávits se dedicaban a financiar gastos públicos generales y los déficits se financiaban con impuestos.

En cuanto a la experiencia internacional, casi todos los países financian ciertas prestaciones mediante impuestos. Esto incluye las prestaciones no contributivas (pensiones asistenciales) y complementos a mínimos. Además muchos de ellos financian parcialmente con impuestos alguna prestación (invalidez, por ejemplo,) los beneficios a algún grupo (agricultores o marineros, por ejemplo) o las cotizaciones de quienes temporalmente no trabajan (quienes cuidan a sus hijos, por ejemplo). Más allá de esto, muchos países están obligados a financiar con impuestos cualquier déficit que resulte del sistema (Reino Unido, Irlanda, Noruega Finlandia, Holanda y Austria) Otros financian con impuestos total o parcialmente una pensión básica (Dinamarca y Suecia). Francia tiene incluso un impuesto asignado para la financiación de las pensiones (y otras prestaciones como la sanidad y las ayudas a las familias). Alemania, por su parte, realiza diversas aportaciones del presupuesto para la financiación de las pensiones. Por un lado realiza una Aportación General y por otro otra específica para complementos ${ }^{29}$.

Dado lo anterior parece claro que no hay razones conceptuales ni comparativas para excluir que una parte de las pensiones se financie con impuestos. La utilización

${ }^{29}$ Tienen dos componentes, el primero se introdujo en 1998 y se financia con parte del IVA. El segundo en 1999 y se financia con impuestos ecológicos. Veáse Börsch-Supan et al (2010) 
de impuestos puede implementarse simplemente con una regla que diga que se cubrirá con impuestos cualquier déficit que resulte del sistema de pensiones.

Por otro lado, una vez se acepta que las pensiones se financien, al menos parcialmente, mediante aportación de ingresos generales del estado la cuestión central de la reforma de las pensiones no será cuanto hay que reducirlas para poder pagarlas con los ingresos que se tienen, sino cuánto hay que ingresar para pagar las pensiones que se consideran justas. Y, como muestra el Cuadro 5, en España, el margen para financiar pensiones mediante impuestos es, bastante amplio. Especialmente si se diseña un sistema fiscal justo y se reduce el fraude.

\subsection{Otras formas de financiación}

Además de los impuestos y las Cotizaciones las pensiones futuras se pueden financiar potenciando el Fondo de Reserva que existe y emitiendo Deuda en el futuro.

A) El Fondo de Reserva es una forma de redistribuir el coste de las pensiones en el tiempo y que las rentas presentes (del trabajo y capital) paguen las pensiones futuras. Si los recursos del fondo se invierten en Deuda Pública nacional el resultado es equivalente a que el Sector Público se comprometa (de forma creíble e irrenunciable) a financiar las pensiones futuras con impuestos futuros. Si, por el contrario se invierte en activos exteriores, la garantía de las pensiones ya no dependerá de los impuestos futuros del país ${ }^{30}$.

B) Deuda. Si a partir del 2030 se emitiera Deuda para financiar las pensiones, esto permitiría trasladar parte del coste de las pensiones de los años de más envejecimiento a los de menos envejecimiento (los posteriores). El coste puede no ser muy elevado. Financiar, por ejemplo 2 puntos del PIB anuales de pensiones durante 20 años, conllevará emitir menos Deuda que la que España ha emitido en cuatro años de crisis financiera.

El problema de este instrumento es que ni en la actualidad ni el futuro previsible, se podría utilizar por las restricciones que los países de la zona euro se han autoestablecido en aras, supuestamente, a favorecer el crecimiento y la estabilidad del euro. Sin embargo, quizá dentro de veinte años estas restricciones no existan o sean más permisivas.

\footnotetext{
${ }^{30} \mathrm{Si}$ se prohíbe al fondo comprar Deuda del Estado, éste deberá buscar otra financiación para esta Deuda (que no se permite comprar al Fondo de Reserva). Y en el futuro para devolver esta Deuda tendrá que aumentar los impuestos en la misma cuantía que si la Deuda la hubiera comprado el Fondo. La diferencia está en que si el Fondo no invierte en Deuda, se evitan las tentaciones de endeudamiento fácil y que las pensiones (aunque no la financiación general del Estado) se desligan de los impuestos nacionales.
} 


\section{El Futuro del Sistema de Pensiones}

El sistema de pensiones es sostenible desde el punto de vista económico (porque absorberá una cantidad moderada de recursos económicos) pero no lo es desde el punto de vista financiero en su diseño actual (porque las cotizaciones no vas a ser suficientes para financiar las pensiones).

Hasta el momento las reformas del sistema de pensiones se han basado en el principio de que las pensiones deben ajustarse a lo que recaudan las cotizaciones a tipos similares a los vigentes. La reforma del 2013 ha llevado este principio al límite y ha introducido una regla de revalorización de las pensiones que, primero, elimina el déficit y luego hace que las pensiones crezcan según lo que se recauda. Además las pensiones se ajustarán según el aumento en la esperanza de vida. Dado que en cualquier escenario plausible las pensiones (a prestaciones constantes) aumentarán más que las cotizaciones esto implica reducciones progresivas y sustanciales de las pensiones. Esta reforma, unida a la del 2011 acaban implicando una reducción sustancial de la pensión, que en el horizonte del 2050 puede caer (en relación a lo que hubieran sido sin reforma) más del $40 \%$. Unas pensiones más bajas que requieren periodos más amplios de cotización a generaciones que han experimentado tasas de paro elevadas durante muchos años, garantiza un futuro con una población envejecida y empobrecida. Peor aún, los jubilados verán caer su renta real desde el momento en que se jubilen porque casi con certeza sus pensiones se revalorizarán casi siempre por debajo de la inflación por lo que los más ancianos serán los peor situados.

Esto es inaceptable no sólo por sus resultados sino porque ignora los derechos morales de los pensionistas a recibir prestaciones similares a las que ellos ayudaron a pagar. En realidad supone que los pensionistas actuales y futuros no tienen ningún derecho a recibir nada. Por ello es necesario que se cambie el principio ético subyacente al sistema de pensiones. El punto de partida debe ser aceptar que los trabajadores tienen derecho a un determinado nivel de pensiones y los ingresos deben ajustarse a dicho nivel de pensiones. El nivel de prestaciones debe decidirse socialmente, pero una opción razonable es que los jubilados reciban prestaciones similares a las que ellos ayudaron a pagar. Esto es compatible con una reducción de las prestaciones vitalicias. Los recursos necesarios pueden provenir de diversas fuentes. Unas cotizaciones más elevadas, más impuestos, un fondo de reserva adecuadamente dotado y, en función de la normativa europea vigente en el futuro, más deuda. Cada uno de estos elementos de financiación implicará una distribución distinta entre generaciones de los costes adicionales del sistema de pensiones debidos al envejecimiento de la población. Así la reducción de las prestaciones vitalicias afecta a los pensionistas cuando se jubilen, los impuestos a las rentas del trabajo y del capital futuros, el Fondo de Reserva a las generaciones actuales, la deuda a las generaciones posteriores a los años de mayor envejecimiento.

Para diseñar un sistema de pensiones que garantizara unos niveles de prestaciones suficientes, serían necesarias las siguientes medidas: 


\section{A) Gastos}

(1) Eliminar el factor de sostenibilidad

(2) Extender la jubilación a los 67 años a toda la población

(3) Eliminar las jubilaciones anticipadas

(4) Establecer una pensión contributiva para cualquiera que haya cotizado (aunque sea menos de quince años). No debería ampliarse más número de años en la base reguladora.

(5) Eliminar el índice de revalorización introducido en la reforma del 2013 y sustituirlo por el IPC.

(6) Establece una cota mínima a la tasa de sustitución definida en términos netos (pensión después de impuestos/salario después de impuestos.

\section{B) Ingresos}

(1). En el corto plazo los recursos del sistema se incrementarían con

(1.1) Un aumento de las cotizaciones a cargo del trabajo de tres puntos y del empresario de un punto. Se destoparían las cotizaciones (sin aumento de prestaciones). A los trabajadores se les compensaría este aumento con el compromiso (3).

(1.2) La creación de una Contribución a la Solidaridad (que, como en Francia, gravara los patrimonios personales y las ventas de las grandes empresas) cuyos recursos se afectarían al sistema de pensiones.

(1.3) Lo que se obtuviera con estos ingresos financiaría las pensiones y el exceso se acumularía en el Fondo de Reserva.

(2) El Fondo de Reserva puede utilizarse coyunturalmente. No obstante, cualquier disposición antes del 2030 debe ser repuesta. A partir de ese año la reposición no será necesaria.

(3) Compromiso de financiar con impuestos generales cualquier déficit del sistema que surja ahora o en el futuro. En todo caso, cualquier reducción de cotizaciones empresariales será compensada con una aportación permanente al sistema de pensiones

(4) Se debe reducir el fraude en las Cotizaciones. En el largo plazo, cuando sea posible, se pasarán cotizaciones de desempleo a pensiones.

(5) Si es viable según los acuerdos de estabilidad vigentes con la UE en ese momento, parte de las pensiones se podrá financiar emitiendo Deuda. 


\section{Bibliografía}

Actualización del Programa de Estabilidad 2012-2015.

Actualización del Programa de Estabilidad 2014-2017.

Rosado, B. y Domínguez, I. (2014). Solvencia Financiera y Equidad en el Sistema de Pensiones Español tras las reformas de 2011 Y 2013. Anales del Instituto de Actuarios Españoles, $3^{\mathrm{a}}$ época, 20, 117-164.

Boletín Oficial de las Cortes Generales (1995). Serie E: Otros Textos 12 de abril de 1995 Núm. 134.

Börsch-Supan, A., Gasche, M. y Wilke, CB, How sensitive is the German public pension system to economic recessions? An answer based on the current financial crisis. Mimeo.

Comisión Europea (2014). The 2012 Ageing Report: Economic and budgetary projections for the27 EU Member States (2010-2060). European Economy $2 \mid 2012$.

Comisión Europea (2015). The 2015 Ageing Report: Economic and budgetary projections for the27 EU Member States2013-2060 European Economy 83|2015.

Comisión Europea (2008). The 2012 Ageing Report: Economic and budgetary projections for the27 EU Member States (2008-2060). European Economy $7 \mid 2008$.

Devesa, J.E; Devesa, M; Encinas. B; Domínguez, I. y R. Meneu (2013). Comparación entre el FEI y el FS propuesto por el Ministerio. www.uv.es/pensiones/docs/factor-sostenibilidad/FEI_FS.pdf.

Fondo de Reserva de la Seguridad Social (2015). http://www.segsocial.es/Internet_1/Estadistica/FondodeReservadelaS48074/index.htm.

González-Páramo, J.M. y Melguizo, A. (2009). Who Bears Social Security Taxes? A Meta-Analysis Approach. Instituto de Estudios Fiscales, P. T. 20/09.

Karabarbounis, L y Neiman, B. (2014). The Global Decline Of The Labor Share, The Quarterly Journal of Economics, 61-103.

Ministerio de Trabajo e Inmigración (2011). Memoria Económica del Anteproyecto de Ley sobre Actualización, Adecuación y Modernización del Sistema de Seguridad Social. 
OCDE (2011). Pension at a glance 2011: Country note.

Presupuesto de la Seguridad Social 2015.

Zubiri, I (2012). Reforma y sostenibilidad del sistema de pensiones: una valoración crítica. Economía española y Protección Social, $N^{o}$. 4, págs. 59-105.

Zubiri, I. (2013). Las cotizaciones sociales. En Impuestos para todos los públicos / coord. por Francisco José Delgado Rivero, Roberto Fernández Llera, 2013, ISBN 978-84-368-2727-9, págs. 135-159.

Zubiri, I. (2013). El sistema de pensiones en la encrucijada: reformulación o liquidación Documentación social, ISSN 0417-8106, Nº 170, págs. 91-119.

Zubiri, I. (2014). El Sistema Fiscal Español Las Reformas Necesarias. Mediterráneo Económico 25, 117-45. 